\title{
PERATURAN DESA DAN SANITASI TOTAL BERBASIS MASYARAKAT PADA OPEN DEFECATION FREE
}

\author{
Denni Kurniawan, Husnul Khotimah* \\ Program Studi Keperawatan, Fakultas Kesehatan, Universitas Nurul Jadid, Jl.KH. Zaini Mun’im Karanganyar \\ Paiton Probolinggo, Jawa Timur, Indonesia 67291 \\ *husnulcrakers@gmail.com (+6285235430683)
}

\begin{abstract}
ABSTRAK
Open Defecation Free atau ODF dapat dikendalikan dengan pengelolaan yang tepat, beberapa cara yang dapat digunakan adalah melibatkan desa untuk membuat Peraturan Desa dan mengaktifkan Sanitasi Total Berbasis Masyarakat (STBM). Penerapan Peraturan Desa dan Pengaktifan Sanitasi Total Berbasis Masyarakat di Dusun Krajan Desa Nogosari Kecamatan Sukosari yang bertujuan untuk merubah kebiasaan masyarakat buang air terbuka menjadi buang air tertutup sehingga dapat tercapai desa ODF. Populasi yang diteliti adalah masyarakat yang berjumlah 114 orang, dengan jumlah sampel 71 sampel. Teknik pengambilan sampel dengan menggunakan purposive sampling. Instrumen yang digunakan koesioner dan observasi. Hasil uji analisa dengan menggunakan uji Spearman Rho didapatkan bahwa p-value 0,000 $<0,05$ maka penerapan Peraturan Desa dan pengaktifan Sanitasi Total Berbasis Masyarakat dapat membantu mewujudkan tercapainya Open Defecation Free.
\end{abstract}

Kata kunci: peraturan desa, sanitasi total berbasis masyarakat, open defecation free

\section{COMMUNITY BASED VILLAGE AND SANITATION REGULATIONS ON OPEN DEFECATION FREE}

\begin{abstract}
Open Defecation Free or ODF can manage properly, some of the methods used is to make Village Regulations and activate Community Based Total Sanitation (STBM). Application of Village Regulations and Community Based Total Sanitation. Activation in Krajan Hamlet, Nogosari Village, Sukosari District, Bondowoso District which aims to change the habits of the community to open defecation into closed defecation so that an ODF Village can be reached. The population that was released was the community that issued 114 people, with a sample of 71 samples. Sampling technique using purposive sampling. The instruments used were questionnaires and observations. The results of the analysis test using the Spearman Rho test obtained that the p-value 0,000 <_05, hence the application of Village Regulations and activation of Community-Based Total Sanitation can help realize the achievement of Open Defection Free.
\end{abstract}

Keywords: village regulations, community based total sanitation, open defecation free

\section{PENDAHULUAN}

Upaya kesehatan wajib puskesmas adalah upaya yang ditetapkan berdasarkan komitmen nasional, regional dan global serta yang mempunyai daya ungkit tinggi untuk peningkatan derajat kesehatan masyarakat. Upaya kesehatan wajib ini harus diselenggarakan oleh setiap puskesmas yang ada di wilayah Indonesia. Upaya STBM di puskesmas mencakup kegiatan penyehatan air, hygiene dan sanitasi makanan dan minuman penyehatan tempat pembuangan sampah dan limbah, STBM pemukiman dan jamban keluarga pengawasan sanitasi tempat-tempat umum dan industri, pengamanan tempat pengelolaan pestisida, klinik sanitasi puskesmas dan pengendalian vektor (Ashari, dkk, 2016).

Banyak jenis program dan intervensi telah dicoba untuk meningkatkan akses pada 
fasilitas sanitasi ini, namun hasil yang dicapai belum secara bermakna dapat menyelesaikan persoalan. Lebih dari tiga puluh tahun, akses terhadap sanitasi di pedesaan tidak berubah. Belajar dari pengalaman-pengalaman tersebut, kemudian dikenalkan metode Sanitasi Total Berbasis Masyarakat (STBM) Metode ini melakukan pendekatan dengan menjadikan masyarakat sebagai subyek, dan dilakukan stimulasi kepada mereka untuk melakukan self assessment terhadap kondisi sanitasi pada komunitas mereka. Tahap selanjutnya adalah memicu mereka untuk berubah dengan cara mengaktifkan motivasi dan arahan dari perangkat desa berupa pembuatan Peraturan Desa yang mengikat tentang STBM (Depkes, 2019).

India merupakan negara terburuk dalam sanitasi masyarakatnya, dan Indonesia menduduki posisi nomer dua (Kompas, 2017). Indikator hasil upaya STBM di Indonesia pada tahun 2018 antara lain persentase penduduk yang memiliki akses terhadap air minum berkualitas sebesar $67 \%$, persentase kualitas air minum yang memenuhi syarat kesehatan $80 \%$, persentase penduduk yang menggunakan jamban sehat sebanyak 59,09\% dan cakupan rumah yang memenuhi syarat kesehatan sebanyak 59,09\% (Depkes, 2014). Sedangkan penyakit yang berhubungan dengan sanitasi sebanyak 4.274.790 kasus dan tertangani $60,4 \%$.

Jawa Timur dengan jumlah desa/kelurahan yang telah melaksanakan STBM sebanyak 6.089 desa atau 71,66 \%. Sedangkan di penyakit berhubungan dengan sanitasi sebanyak 604.779 kasus dan tertangani 57\% (Kesehatan Indonesia, 2017). Di Bondowoso cakupan kegiatan program STBM antara lain, akses sanitasi layak (jamban sehat) sebanyak 58,97\%, jumlah desa yang melaksanakan STBM sebanyak 209 desa dan 10 kelurahan $(56,87 \%)$ dan desa Stop BABS sebanyak 17 desa (7\%) dan penyakit yang berhubungan dengan sanitasi adalah 30.563 kasus dan tertangani 100\% (Kesehatan Bondowoso, 2018).

Keberhasilan suatu program maka perlu pembuatan peraturan yang mengikat. Peraturan desa adalah peraturan perundangundangan yang ditetapkan oleh Kepala Desa setelah dibahas dan disepakati bersama Badan Permusyawaratan Desa (KDPDTT, 2015). Peraturan tersebut merupakan suatu upaya pengawasan dan pengikat dalam rangka menilai keberhasilan desa dan salah satunya adalah penyuksesan STBM sebagai program kerja sebuah institusi terendah di desa dalam rangka pencapaian tujuan Desa BABs atau ODF. Bedasarkan fenomena diatas peneliti tertarik untuk melakukan penelitian tentang "Hubungan Peraturan Desa dan Sanitasi Total Berbasis Masyarakat (STBM) terhadap Open Defecation Free (ODF) di Dusun Krajan Desa Nogosari Kecamatan Sukosari Bondowoso.

\section{METODE}

Penelitian menggunakan metode analisis korelasi atau hubungan, dengan pendekatan cross sectional, dimana peneliti melakukan observasi atau pengukuran variabel pada satu waktu. Populasi dalam penelitian ini adalah kepala keluarga di Dusun Krajan Desa Nogosari Kecamatan Sukosari, dengan jumlah populasi 114 dan sampel yang diambil sebanyak 71 responden. Tehnik pengambilan sampel dilakukan secara purposive sampling. Penelitian dilakukan di Dusun Krajan Desa Nogosari pada bulan April sampai dengan Mei 2019. Instrument dalam penelitian ini adalah kuesioner dan observasi dengan skala gutman. Pengolahan data pada penelitian ini menggunakan tehnik uji statistik Spearman's Rho, dengan program Statistical Program for Social Solution (SPSS). Tingkat kemaknaan/signifikasi $\alpha=$ 0,05 , dimana jika $\mathrm{P}$ value hitung $>0,05$ maka $\mathrm{H}_{1}$ ditolak, dan jika $\mathrm{P}$ value $<0,05$ maka $\mathrm{H}_{1}$ diterima. 
HASIL

Tabel 1.

Distribusi berdasarkan peraturan desa $(n=71)$

\begin{tabular}{lccc}
\hline \multicolumn{1}{c}{ Peraturan desa } & f & $\%$ \\
\hline Baik & & 51 & 72 \\
\hline Tidak & 2028 & & \\
\hline
\end{tabular}

Tabel 1 dari 71 responden sebagian banyak

responden yaitu 51 responden (72\%)

memiliki kriteria penilaian baik.

Tabel 2.

Distribusi berdasarkan sanitasi total berbasis masyarakat $(n=71)$

\begin{tabular}{lcc}
\hline Sanitasi total berbasis masyarakat & f & $\%$ \\
\hline Baik & 53 & 75 \\
\hline Tidak baik & 18 & 25 \\
\hline
\end{tabular}

Tabel 2 dari 71 responden sebagian banyak

responden yaitu 53 responden $(75 \%)$

memiliki penilaian baik

Tabel 3.

Distribusi berdasarkan Open Defecation Free (ODF) $(\mathrm{n}=71)$

\begin{tabular}{lcc}
\hline \multicolumn{1}{c}{ Open Defecation Free } & f & $\%$ \\
\hline ODF & 50 & 70 \\
\hline Tidak & 21 & 30 \\
\hline
\end{tabular}

Tabel 3 dari 71 responden sebagian

banyak responden yaitu 50 responden

(70\%) ODF.

Tabel 4.

Hubungan peraturan desa dan sanitasi total berbasis masyarakat (STBM) terhadap open defecation free (ODF) $(\mathrm{n}=71)$

\begin{tabular}{lcc}
\hline Variabel & $\mathrm{N}$ & Asymp. Sig. (2-tailed) \\
\hline Peraturan desa - ODF & 71 & 0,000 \\
\hline STBM - ODF & 71 & 0,000 \\
\hline
\end{tabular}

Berdasarkan tabel 4, didapatkan bahwa nilai signifikan antara Peraturan Desa terhadap Open Defecation Free (ODF) adalah 0.000 yang berarti $<0.05$ yang berarti ada hubungan yang signifikan antara peraturan desa dengan Open Defecation Free (ODF). Berdasarkan tabel tersebut juga didapatkan bahwa nilai signifikan antara Sanitasi Total Berbasis Masyarakat (STBM) terhadap Open Defecation Free (ODF) adalah 0.000 yang berarti $<0.05$ yang berarti ada hubungan yang signifikan antara Sanitasi Total Berbasis Masyarakat (STBM) dengan Open Defecation Free (ODF).

\section{PEMBAHASAN \\ Interpretasi Peran Peraturan Desa}

Hasil diatas pada tabel 1 didapatkan data dari 71 responden rata-rata memiliki penilaian baik sebanyak 51 responden (72\%), dan tidak baik sebanyak 20 responden $(28 \%)$. Sebanyak 20 responden $(28 \%)$ yang penilaiannya tidak baik ratarata memiliki kesamaan jawaban, yaitu jarang berpartisipasi dalam setiap kegiatan yang ada didesa, lebih mementingkan kepentingan pribadi dibanding kepentingan bersama, tidak mentaati semua aturan yang sudah disepakati, jarang mengikuti kerja bakti desa, dan penyelesaian masalah tidak melewati musyawarah. Dari 20 responden 
yang tidak baik rata-rata memiliki pendidikan SD sebanyak 15 responden, SMP 3 responden, SMA 2 responden, dan Perguruan Tinggi 1 reponden.

Menurut peneliti dengan adanya peraturan desa, akan mengakomodir aspirasi masyarakat tentang peraturan-peraturan desa yang lainnya serta akan terjadi peningkatan kepatuhan masyarakat tentang pembangunan di suatu wilayah desa terutama yang berhubungan dengan masalah kesehatan terkhusus tentang cara membuang air besar yang benar. Tujuan dari Peraturan desa adalah sebagai penjabaran lebih lanjut dari peraturan perundang-undangan yang lebih tinggi dengan memperhatikan kondisi sosial budaya masyarakat setempat (Vita Health, 2006).

Pada intinya Peraturan Desa bukanlah sebuah kegiatan yang dilaksanakan sematamata untuk memenuhi tugas yang diemban oleh Kepala Desa dan BPD, melainkan benar-benar untuk menyelesaikan permasalahan dan memberikan manfaat bagi masyarakat desa. Peraturan Desa sebagai salah satu instrumen hukum yang mengatur masyarakat harus memiliki wibawa sehingga dipatuhi oleh masyarakatnya sendiri.

\section{Interpretasi Sanitasi Total Berbasis Masyarakat (STBM)}

Pada tabel 2 dari 71 responden didapatkan 53 responden $(75 \%)$ memiliki sanitasi yang baik dan 18 responden (25\%) masih belum baik. Sebanyak 18 responden (25\%) yang tingkat STBM nya masih rendah rata-rata memiliki kesamaan jawaban, yaitu masih beranggapan tidak hanya buang air besar dijamban saja yang sehat, buang air besar sembarangan tidak menyebabkan pencemaran lingkungan, tidak setuju dengan mewajibkan setiap rumah memiliki jamban, tidak setuju dengan adanya peringatan dilarang buang air besar dan buang sampah ditempat-tempat umum, dan tidak sependapat apabila mendirikan jamban dapat memutuskan rantai penularan penyakit. Dari 18 responden yang berpendidikan SD 13 responden, SMP 3 responden, dan Perguruan Tinggi 2 responden, tingkat penghasilan 10 responden berkisar 300 ribu sampai dengan 1 juta, 6 responden 1 juta sampai dengan 2 juta, dan 2 responden diatas 2 juta tiap bulannya.

Menurut Peneliti Sanitasi Total Berbasis Masyarakat, memiliki konsep untuk mendorong peran aktif masyarakat dalam memaksimalkan pembuangan limbah sanitasi rumah tangga masyarakat. Untuk itu, perhatian terhadap lingkungan merupakan hal yang mutlak untuk terus dikerjakan agar terciptanya lingkungan yang sehat guna meningkatkan status kesehatan masyarakat. Sanitasi lingkungan yang buruk secara langsung maupun tidak langsung akan menimbulkan masalah kesehatan.

Sanitasi Total Berbasis Masyarakat (STBM) merupakan pendekatan untuk merubah perilaku higiene dan sanitasi melalui pemberdayaan masyarakat dengan metode pemicuan. Program STBM memiliki indikator outcome dan output. Indikator outcome STBM yaitu menurunnya kejadian penyakit diare dan penyakit berbasis lingkungan lainnya yang berkaitan dengan sanitasi dan perilaku. Sedangkan indikatoroutput STBM adalah sebagai berikut : Setiap individu dan komunitas mempunyai akses terhadap sarana sanitasi dasar sehingga dapat mewujudkan komunitas yang bebas dari buang air di sembarang tempat, setiap rumah tangga telah menerapkan pengelolaan air minum dan makanan yang aman di rumah tangga, setiap rumah tangga dan sarana pelayanan umum dalam suatu komunitas, setiap rumah tangga mengelola limbahnya dengan benar dan, setiap rumah tangga mengelola sampahnya dengan benar.

Pembenahan pada lingkungan dan karakter masyarakat desa bukan merupakan perkara mudah, seperti membalikkan telapak 
tangan, namun merupakan permasalahan yang rumit dan kompleks, karena selalu menghadapi tantangan, baik dari dalam maupun dari luar masyarakat. Tantangan terbesar yang dihadapi pemerintah adalah masalah sosial budaya dan perilaku masyarakat, seperti Buang Air Besar di sembarang tempat, khususnya ke badan air yang digunakan untuk mencuci, mandi, dan kebutuhan higienis lainnya.

\section{Interpretasi Open Defecation Free (ODF)}

Pada tabel 3 didapatkan dari 71 responden yang sudah berprilaku tidak BAB di sembarang tempat sebanyak 50 responden (70\%), dan 21 responden (30\%) lainnya masih belum. Sebanyak 21 responden $(30 \%)$ yang belum ODF masih buang air besar sembarangan dan belum memanfaatkan jamban, jarang menggunakan sabun untuk cuci tangan, membuang sambah sembarangan, dan tidak memiliki tempat kusus untuk penampungan sampah. Dari 21 responden yang tidak ODF rata-rata memiliki pendidikan SD 15 responden, SMP 4 responden, dan SMA 2 responden, rata-rata penghasilan 11 responden berkisar 300 ribu sampai dengan 1 juta, 7 responden 1 juta sampai dengan 2 juta, dan 3 responden lebih dari 2 juta setiap bulannya.

Menurut Peneliti bahwa satu komunitas/masyarakat dikatakan telah ODF jika : Semua masyarakat telah BAB hanya di jamban dan membuang tinja/kotoran bayi hanya ke jamban, tidak terlihat tinja manusia di lingkungan sekitar, tidak ada bau tidak sedap akibat pembuangan tinja/kotoran manusia, ada peningkatan kualitas jamban yang ada supaya semua menuju jamban sehat, ada mekanisme monitoring peningkatan kualitas jamban, ada penerapan sanksi, peraturan atau upaya lain oleh masyarakat untuk mencegah kejadian BAB di sembarang tempat, serta adanya mekanisme monitoring umum yang dibuat masyarakat untuk tercapainya seluruh KK mempunyai jamban sehat.
Open Defecation Free (ODF) adalah kondisi ketika setiap individu dalam komunitas tidak buang air besar sembarangan, Pembuangan tinja yang tidak memenuhi syarat sangat berpengaruh pada penyebaran penyakit berbasis lingkungan, sehingga untuk memutuskan rantai penularan ini harus dilakukan rekayasa pada akses ini. Agar usaha tersebut berhasil, akses masyarakat pada jamban (sehat) harus mencapai 100\% pada seluruh komunitas. Perilaku ODF diikuti dengan pemanfaatan sarana sanitasi yang saniter berupa jamban sehat (Permenkes, 2014).

\section{Analisis Hubungan Peraturan Desa dan Sanitasi Total Berbasis Masyarakat (STBM) terhadap Open Defecation Free (ODF)}

Berdasarkan tabel 4 didapatkan nilai signifikan diantara keduanya adalah 0.000 yang berarti $<0.05$ yang berarti ada hubungan antara peraturan desa dengan Open Defecation Free (ODF).

Berdasarkan tabel 5.10 di atas, didapatkan nilai signifikan diantara keduanya adalah 0.000 yang berarti $<0.05$ yang berarti ada hubungan antara Sanitasi Total Berbasis Masyarakat (STBM) dengan Open Defecation Free (ODF). Hasil statistik tersebut menyatakan bahwa ada Hubungan Peraturan Desa dan Sanitasi Total Berbasis Masyarakat (STBM) terhadap Open Defecation Free (ODF) di Dusun Krajan Desa Nogosari Kecamatan Sukosari Bondowoso.

Menurut analisa peneliti bahwa sangat diperlukan peraturan desa yang mengikat masyarakat untuk mengubah perilaku yang buruk menjadi perilaku yang sehat terutama masalah buang air besar. Serta dukungan masyarakat melalui sanitasi mandiri yang akan berdampak kebaikan dan kembali 
kepada masyarakat kembali tentang manfaat dan keuntungannya. Oleh karena itu, diperlukan stimulan serta promosi yang benar-benar bisa dipahami dan mudah mudah dimengerti serta dapat ditekan biayanya, agar tercipta penilaian keluarga sehat serta meningkatkan kualitas hidup yang lebih baik. Melihat dari hasil Peraturan Desa dan STBM yang dirasa masih belum mencapai target hal ini bisa dipengaruhi juga oleh beberapa factor, diantaranya faktor pendidikan karena beberapa masyarakat banyak yang status pendidikannya SD, kemudian faktor ekonomi beberapa masyarakat masih mempunyai penghasilan yang minim berkisar 300 ribu sampai dengan 1 juta per bulan dan juga factor kebiasaan yang membudaya yaitu buang air besar disungai ataupun dilapangan, maka diperlukan adanya pendekatan dan peraturan serta stimulan-stimulan lain untuk meningkatkan ODF di Dusun Krajan khususnya dan Desa Nogosari pada umumnya.

Hal ini sesuai dengan Peraturan Menteri Pembangunan daerah Tertinggal dan Transmigrasi bahwa peraturan perundangundangan yang ditetapkan oleh Kepala Desa setelah dibahas dan disepakati bersama Badan Permusyawaratan Desa Peraturan desa dibentuk dalam rangka penyelenggaraan pemerintahan desa, dengan demikian maka pemerintahan desa harus merupakan penjabaran lebih lanjut dari peraturan-peraturan perundangundangan yang lebih tinggi dan tidak boleh bertentangan dengan kepentingan umum dan/atau peraturan perundang-undangan yang lebih tinggi serta harus memperhatikan kondisi sosial budaya masyarakat desa setempat dalam upaya mencapai tujuan pemerintahan, pembangunan dan pelayanan masyarakat jangka panjang, menengah dan jangka pendek. Terkhusus masalah sanitasi masyarakat tentang merubah perilaku buang air besar sembarang menjadi buang air besar tertutup yang akan berdampak kebaikan kepada masyarakat sendiri. Hal ini juga bersinergi dengan Prinsip - Prinsip STBM yang telah tertuang dalam Peraturan Menteri Kesehatan.

Peraturan Desa dan STBM akan sukses menjadikan masyarakat merubah perilaku dari buang air besar sembarang menjadi buang air besar tertutup. Tentunya dengan dukungan dari pemerintah desa serta dukungan dari Puskesmas dan berjalannya STBM, maka ODF akan cepat tercapai (Siti Sholikhah, 2012).

\section{SIMPULAN}

Rata-rata responden mengatakan pentingnya peraturan desa adalah $72 \%$, mengatakan pentingnya Sanitasi Total Berbasis Masyarakat adalah $75 \%$ dan sudah berperilaku Open Defecation Free (ODF) adalah $70 \%$. Ada Hubungan Peraturan Desa dan Sanitasi Total Berbasis Masyarakat (STBM) terhadap Open Defecation Free (ODF) di Dusun Krajan Desa Nogosari Kecamatan Sukosari Bondowoso yang diperoleh dari analisa statistik $p<0,05$, nilai $p=0,000$.

\section{DAFTAR PUSTAKA}

Antonius B. Luju. (2015). www.facebook.com/8333220667444 25/posts/peraturan-kepala-desanitanomor-6-tahun-

2015tentangpenyelenggaraan-stbmdi-desa-/847122375364394/.

Rencana Pembangunan Jangka Menengah Desa Nita tahun 20142019.

Ashari, dkk. (2016). Evaluasi Program Sanitasi Total Berbasis Masyarakat Di Kabupaten Mamuju, Jurnal Poltekkes Mamuju

Depkes.

http://www.depkes.go.id/article/print/ 


\section{3/menuju-100-akses- sanitasi-indonesia-2019.html}

Halim, Hamzah. Kemal Redindo. 2009. Cara Praktis Menyusun dan Merancang Peraturan Daerah. Kencana Media Group. Jakarta.

Kementerian Kesehatan RI. (2018). Pedoman Teknis Analisis Dampak. Kesehatan Lingkungan. Jakarta: Kementerian Kesehatan.

Kepmenkes

RI

No.852/MENKES/SK/IX/2008

Lukman,(2018).

http://kominfo.jatimprov.go.id/read/u mum/lima-daerah-di-jatim-raihpenghargaan-stbm-berkelanjutandari-kemenkes

Muhammad Abduh Tuasikal, MSc. (2010). https://rumaysho.com/1034-10-adabketika-buang-hajat.html

Notoatmojo, Soekidjo. (2012). Metodologi Penelitian dan Kesehatan. Rineka Cipta, Jakarta

Notoatmojo, Soekidjo. (2012). Metodologi Penelitian dan Kesehatan. Rineka Cipta, Jakarta

Nursalam. (2008). Konsep dan Penerapan Metodologi Penelitian Ilmu Keperawatan. Salemba Mediaka. Jakarta.

Peraturan Menteri Desa Pembangunan daerah Tertinggal dan Transmigrasi Republik Indonesia Nomor 3. (2015). Tentang Pendamping Desa. Jakarta

Peraturan Menteri Kesehatan Republik Indonesia Nomor 3 Tahun 2014

Peraturan Pemerintah Republik Indonesia Nomor 43 Tahun 2014 Tentang Peraturan Pelaksanaan UndangUndang Nomor 6 Tahun 2014 Tentang Desa
Peraturan Desa Ngumbul Kecamatan Tulakan Kabupaten Pacitan Nomor : 04 Tahun 2015 Tentang Pelaksanaan Program Sanitasi Total Dan Pemasaran Sanitasi

Percik, Majalah. (2012). Sanitasi Total Berbasis Masyarakat (STBM), Jakarta

Profil Kesehatan . ( 2016 ) Kabupaten Bondowoso, Bondowoso Jawa Timur

Soeprapto, Maria Farida Indrati.(2010). Ilmu Perundang-undangan: Jenis, Fungsi, dan Materi Muatan, Kanisius, Yogyakarta.

Solikhah, Siti. (2012). Hubungan Pelaksanaan Program Odf (Open Defecation Free) Dengan Perubahan Perilaku Masyarakat Dalam Buang Air Besar Di Luar Jamban Di Desa Kemiri Kecamatan Malo Kabupaten Bojonegoro. Jurnal STIKE Muhammadiyah Lamongan.

World Bank, (2017). Water and Sanitation Program 
Jurnal Penelitian Perawat Profesional, Volume 1 No 1 Hal 81 - 88, November 2019 Global Health Science Group 